\title{
Apoptosis during goitre involution - the role of $\mathrm{BCl}-2$
}

\author{
V A Patel ${ }^{1}$, D J Hill ${ }^{2,3}$, M C Sheppard ${ }^{1}$, J-F Wang ${ }^{3}$, A Logan ${ }^{1}$ and \\ M C Eggo ${ }^{1}$ \\ ${ }^{1}$ Department of Medicine, Queen Elizabeth Hospital, University of Birmingham, Birmingham B15 2TT, UK \\ ${ }^{2}$ MRC Group in Foetal and Neonatal Health and Development, Lawson Research Institute, St Joseph's Health Centre, 268 Grosvenor Street, London, \\ Ontario N6A 4V2, Canada \\ ${ }^{3}$ Department of Medicine, University of Western Ontario, London, Ontario N6A 5A5, Canada \\ (Requests for offprints should be addressed to Dr M C Eggo, Department of Medicine, Queen Elizabeth Hospital, University of Birmingham, \\ Birmingham B15 2TT, UK; Email: m.c.eggo@bham.ac.uk) \\ (V A Patel is now at Department of Medicine, Division of Cardiovascular Medicine, Addenbrooke's Hospital, University of Cambridge, Cambridge CB2 2QQ, \\ UK)
}

\begin{abstract}
Goitrogenesis is accompanied by hyperplasia and hypertrophy and involves tissue remodelling and angiogenesis. During the involution of the goitre there must be removal of this increased thyroid volume, in addition to further remodelling, which may involve apoptosis. We investigated apoptosis in the involuting rat thyroid using male Fisher rats that were on a goitrogenic regimen for 14 days and then returned to a normal diet. Thyroid weights increased fourfold with the goitrogenic regimen. During involution, the largest decrease in weight was between day 2 and day 4 after withdrawal of treatment. After 34 days of involution, the thyroid weight plateaued, but had not returned to control values. High levels of Bcl-2 immunoreactivity were observed in normal and goitrous rat thyroids. These high levels were significantly reduced at 2 days of involution, after which high levels of Bcl-2 immunoreactivity returned. In situ end-labelling of apop-
\end{abstract}

totic cells showed that there was an increase in the number of cells undergoing DNA fragmentation during goitrogenesis $(1 \cdot 0 \pm 0 \cdot 8$ cells $/ 100$ cells, $n=9)$ compared with controls, in which no positive staining was observed. After 2 days of goitrogen withdrawal, there was a further fourfold increase in the number of in situ end-labelled cells (day 16: $4 \cdot 1 \pm 1 \cdot 7, n=9$ ). Numbers of positive cells returned to low levels after 4 days of involution (day 18: $0 \cdot 3 \pm 0 \cdot 8, n=9)$. Using antiserum to apoptosis-specific protein, we found increased immunoreactivity during goitrogenesis and after 2 days of involution that was localised predominantly with the stromal and vascular tissue at both time points. The data show that rapid downregulation of Bcl-2 accompanies thyroid involution, which involves increased levels of apoptosis within the stromal compartment.

Journal of Endocrinology (2000) 164, 323-330

\section{Introduction}

Apoptosis or programmed cell death (Kerr et al. 1972) is a vital process during development and tissue homeostasis. Apoptotic cell death is characterised by morphological changes detectable by light and electron microscopy, such as the shrinkage of the cell membrane, chromatin condensation, cellular fragmentation and, finally, engulfment of the apoptotic cells by neighbouring cells. There have been several studies showing apoptosis in the thyroid, particularly with regard to the Fas-Fas ligand system, in autoimmune thyroid diseases (Kotani et al. 1995, Tanimoto et al. 1995). However, few studies have investigated apoptosis during thyroid involution.

Goitre can be induced experimentally in the rat by the administration of the goitrogen, methylmercaptoimidazole (MMI) and a low-iodine diet, which both act to reduce the circulating thyroid hormones. Hypertrophy and hyperplasia characterise the goitre produced (Wollman \& Breitman 1970, Wynford-Thomas et al. 1982a), and there is an angiogenic response to support the growing mass of tissue (Patel et al. 1996). In goitrogen-treated rats, apoptosis was found to be increased during goitrogenesis and involution, which was accompanied by increased expression of Fas (Riesco et al. 1998, Tamura et al. 1998); however, the contribution of Bcl-2 to tissue homeostasis was not investigated. A previous study on goitre involution has shown that there is a small reduction in follicular cell number, but a large reduction in thyroid volume, after a 25-day involution period (Wynford-Thomas et al. 1982b). Another study investigating rat thyroids 2 weeks after goitrogen removal showed a 55\% reduction in DNA content (Wollman \& Breitman 1970); hence, there was significant cell loss, presumably through the stromal cell compartment.

The anti-apoptotic factor, $\mathrm{Bcl}-2$, and related cytoplasmic proteins are key regulators of the apoptotic process. 
There are 15 members of the Bcl-2 family that have been identified in mammalian cells and viruses (Boise et al. 1995, Adams \& Cory 1998, Reed 1998). Those most similar to Bcl-2 promote cell survival by inhibiting the adapter proteins required for the activation of proteases called caspases, which dismantle the cell by breaking up the structural proteins (Zou et al. 1997, Pan et al. 1998). Bcl-2 is localised to the cytoplasmic face of the mitochondrial outer membrane, endoplasmic reticulum and nuclear envelope, and may interfere with the flux of small proteins or molecules through these membranes (Zou et al. 1997, Green \& Reed 1998, Zamzami et al. 1998). Studies on Bcl-2 in the thyroid have concentrated on its significance in neoplasia. They showed that the more advanced carcinomas overexpressed Bcl-2 (Pollina et al. 1996, Manetto et al. 1997, Moore et al. 1998) and thus may be a useful tool with which to assess the prognosis of the disease.

A novel marker of apoptosis is the apoptosis-specific protein (ASP). ASP is a $45 \mathrm{kDa}$ protein that is highly and specifically expressed in human and rodent cells undergoing apoptosis (Grand et al. 1995). It is not expressed in viable or necrotic cells, and is believed to be associated with the cytoskeleton. The aim of this study was to examine apoptosis during goitrogenesis and involution in rat thyroids, and to correlate this with expression of Bcl-2 and ASP.

\section{Methods}

\section{Animal model}

Fisher rats were separated into two groups: group 1, forming a control group, received normal rat chow $(1 \cdot 84$ p.p.m. iodine) and plain tap water; group 2 received a low-iodine diet ( 0.05 p.p.m. iodine) and methimazole $(0 \cdot 01 \% \mathrm{w} / \mathrm{v})$ in the drinking water. Food and water were available ad libitum to both groups. Some of the animals from both groups were killed by carbon dioxide asphyxiation after 14 days. Group 2 animals were returned to a control diet and killed at 2, 4, 6, 8, 11, 16 and 34 days after removal of the goitrogen. The remaining animals from group 1 were killed at day 48 .

All procedures had prior approval of the animal care committee of the University of Western Ontario, Canada. Young adult male Fisher rats weighing 250-340 g were obtained from Charles River, St Constant, Quebec, Canada.

\section{Tissue processing}

Body weight and wet weight of the excised thyroid lobes were recorded. Dissected tissue was fixed for immunohistochemistry by immersion in $4 \%(\mathrm{w} / \mathrm{v})$ paraformaldehyde/ $0 \cdot 2 \%$ glutaraldehyde in PBS $(0 \cdot 0027 \mathrm{M} \mathrm{KCl}$ and $0 \cdot 137 \mathrm{M}$

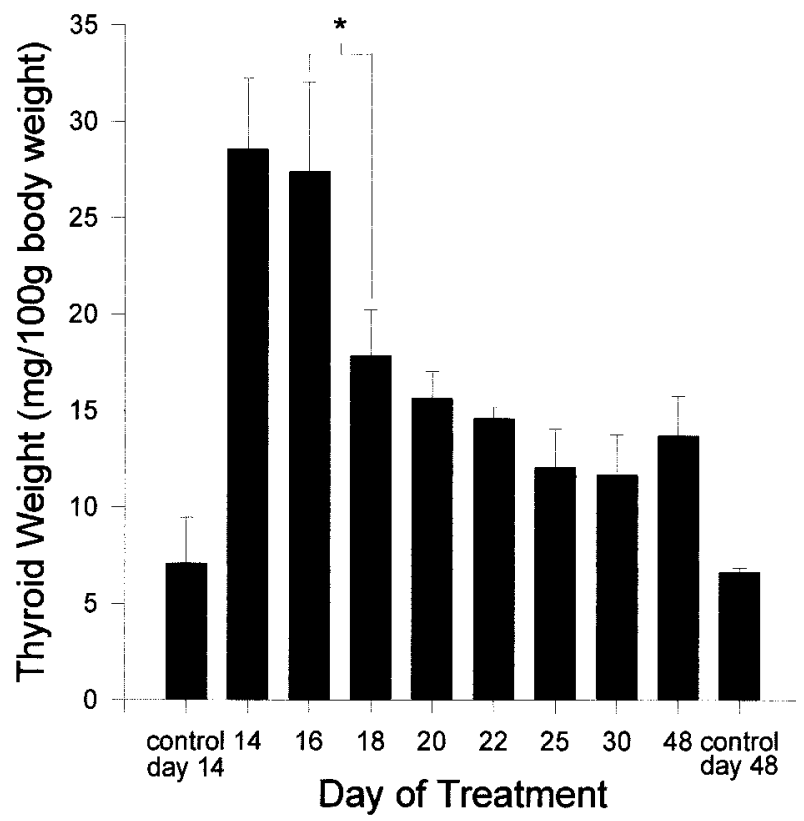

Figure 1 Wet weight of the thyroid gland (expressed per $100 \mathrm{~g}$ body weight) against days of treatment, showing the changes in the thyroid weights from rats in this model (mean \pm S.D., $n=5$ ). Animals were given goitrogen and a low-iodine diet for 14 days to induce goitre. They were returned to a control diet at day 14 and the thyroid allowed to involute for 34 days. After 2 days of involution, there was no significant decrease in thyroid weight. The major decrease in thyroid weight in this model occurred between days 2 and 4 of involution, after which there was a more gradual decrease. The thyroid weight stabilised at about twice the weight of the control thyroid at the same time point, suggesting a new resistant population of cells had survived the involution. ${ }^{*} P<0 \cdot 05$.

$\mathrm{NaCl}$ in $10 \mathrm{mM}$ sodium phosphate, $\mathrm{pH} \mathrm{7.4)} \mathrm{for} 24 \mathrm{~h}$, followed by two washes in PBS, each for $24 \mathrm{~h}$. The tissue was incubated in 30\% (w/v) sucrose in PBS for 5 days before dehydration in $70 \%(\mathrm{v} / \mathrm{v})$ ethanol and embedding in paraffin wax. All treatments were at $4{ }^{\circ} \mathrm{C}$.

In situ assessment of apoptosis

An in situ apoptosis detection kit (Apoptag; Oncor, Gaithesburg, MD, USA) was used for peroxidase staining of $5 \mu \mathrm{m}$ paraffin-embedded tissue sections. This method utilises the free $3^{\prime}-\mathrm{OH}$ DNA ends generated by DNA fragmentation in apoptotic cells. The procedure was performed according to the manufacturer's instructions. The percentage of apoptotic cells was determined from three fields of view, which were selected randomly.

\section{Immunocytochemistry}

Paraffin sections of rat thyroid $(5 \mu \mathrm{m})$ were mounted on glass microscope slides, the paraffin removed with xylene, 

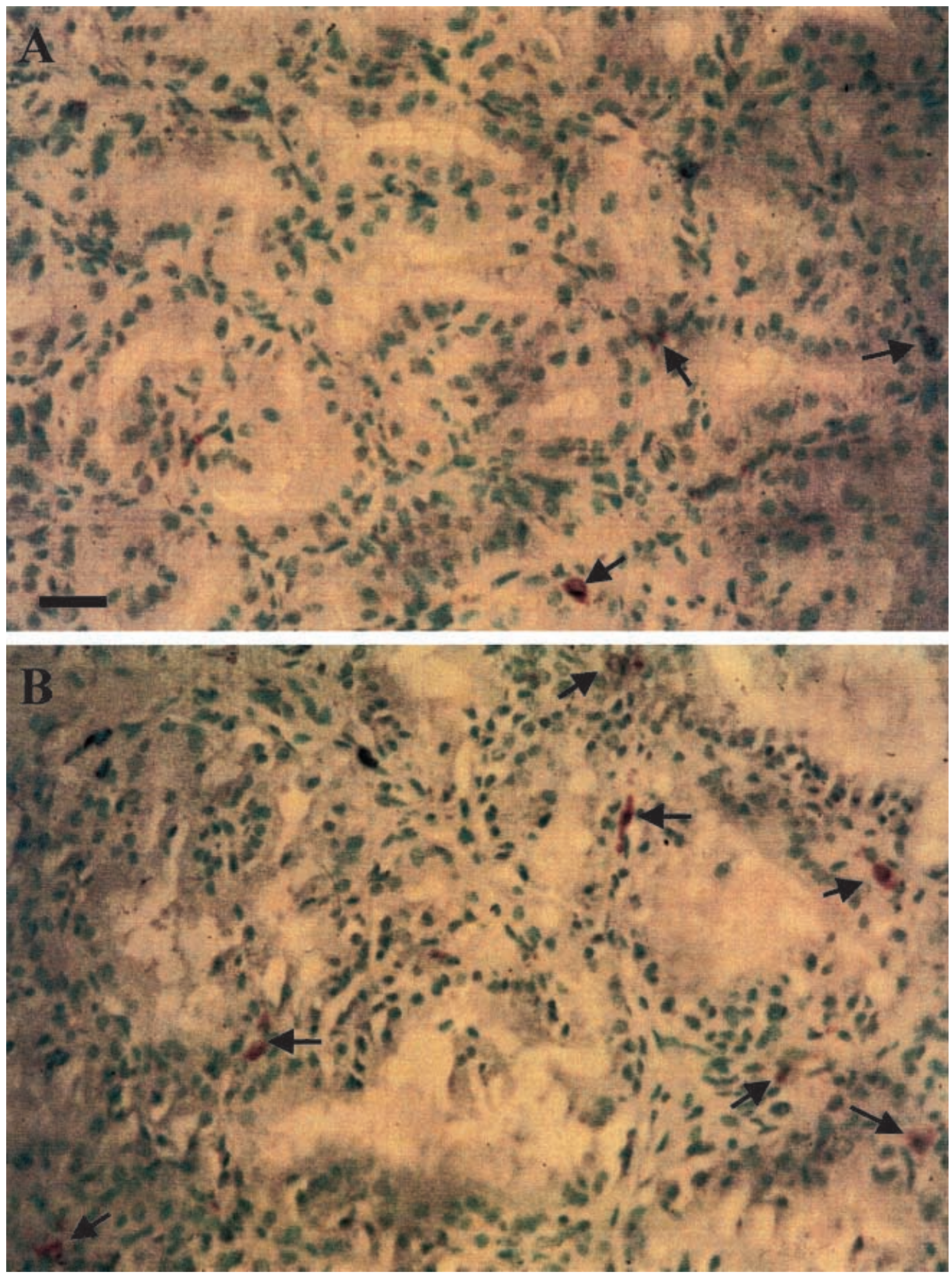

Figure 2 Micrographs of Apoptag in situ end-labelling of (A) goitrogenic, day 14 and (B) 2 days involuted, day 16 rat thyroids showing increased apoptosis. Arrows point to brown-stained apoptotic cells. Bar represents $5 \mu \mathrm{m}$.

and the slides rehydrated in a descending ethanol series (100, 90 and 70\%). Immunohistochemistry was performed using the avidin-biotin peroxidase method (Hsu et al. 1981). After being washed in PBS, sections were incu- bated in $1 \%(\mathrm{v} / \mathrm{v})$ hydrogen peroxide in PBS for $15 \mathrm{~min}$ to eliminate endogenous peroxidase activity, followed by $5 \%$ $(\mathrm{w} / \mathrm{v})$ BSA in PBS for $15 \mathrm{~min}$ to block non-specific binding. Slides were then incubated with a rabbit Bcl-2 
antibody (Santa Cruz Biotechnology, La Jolla, CA, USA) or rabbit ASP antibody (a kind gift from Dr C Gregory, Department of Immunology, University of Birmingham, UK) diluted in PBS containing 2\% (w/v) BSA, overnight at $4{ }^{\circ} \mathrm{C}$ in a humidified chamber. Biotinylated goat antirabbit immunoglobulin $(1: 500$ dilution) was applied for $1.5 \mathrm{~h}$ at $22^{\circ} \mathrm{C}$. After a further wash in PBS, slides were incubated with avidin and biotinylated peroxidase for $1 \mathrm{~h}$ at $22{ }^{\circ} \mathrm{C}$, and washed in PBS. Bcl-2 immunoreactivity was localised using freshly prepared 3,3' diaminobenzidine $(1.89 \mathrm{mmol} / 1$ containing $0.03 \%(\mathrm{v} / \mathrm{v})$ of $30 \%(\mathrm{v} / \mathrm{v})$ hydrogen peroxide). The reaction was quenched by washing in excess PBS and sections were lightly counterstained with haematoxylin, dehydrated in ascending ethanol, cleared with xylene, mounted under glass coverslips and assessed by light microscopy.

Control incubations during immunohistochemistry included the substitution of the primary antibody with non-immune, protein A-Sepharose-purified rabbit $\operatorname{IgG}$, and omission of the biotinylated secondary antibody.

\section{Immunohistological quantification}

This was achieved utilising point counting with a 100 point graticule in the eyepiece of a microscope (Zeiss, Germany) set at a magnification of $\times 400$. Three fields of view on each thyroid were randomly chosen, counted and the totals summed to give a value for each rat in the study. Photographic figures show a representative section of part of one field of view.

\section{Data analysis}

Results are presented as mean \pm s.D. Differences between groups were analysed using Student's $t$-test. All tests were two-tailed and $P$ values $\leq 0.05$ were considered significant.

\section{Results}

\section{Goitre involution model}

Figure 1 shows the wet weights of the rat thyroids in this model. The thyroid weights increased fourfold after 14 days of the goitrogenic regimen. After the rats were returned to a control diet, the largest decrease in thyroid weight was between day 2 and day 4 after withdrawal of treatment. There was a gradual reduction in thyroid weight over the next 14 days. After 34 days of involution, the thyroid weight plateaued, but at twice the weight of the control thyroids at the same time point.

In situ end-labelling and quantification of apoptotic cells

Figure 2 shows the results of the apoptosis detection method using in situ end-labelling. The photographs show

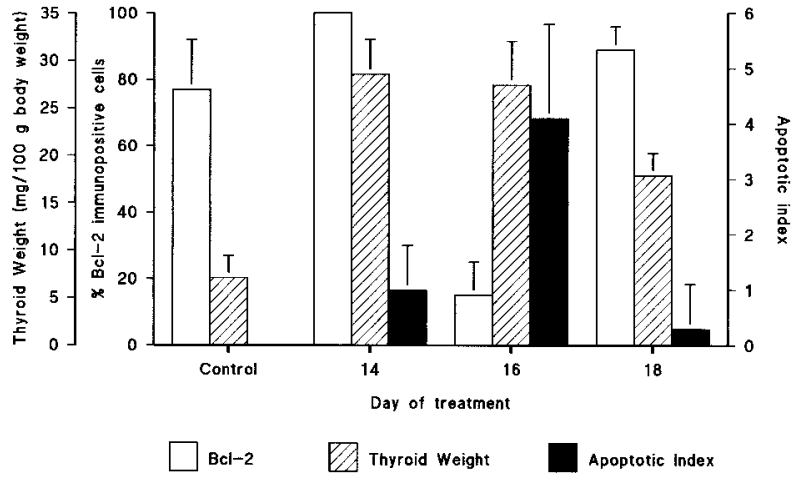

Figure 3 Plot obtained from point counting the number of $\mathrm{BCl}-2$ immunopositive follicular cells and the number of apoptotic cells per 100 cells (apoptotic index). Data show that a downregulation of $\mathrm{Bcl}-2$ within the thyroid accompanied increased apoptosis after 2 days of involution (day 16).

the location of brown-stained apoptotic cells at the stage of DNA fragmentation. There was an increase in the number of cells undergoing DNA fragmentation during goitrogenesis (Fig. 2A, day 14) compared with control thyroids, in which no positive staining was observed (photograph not shown). Figure $2 \mathrm{~B}$ shows rat thyroid tissue 2 days after withdrawal of goitrogen (day 16), in which we observed a further fourfold increase in the number of in situ endlabelled cells. Numbers of positive cells returned to control values after 4 days of involution (photograph not shown). The amount of apoptosis was confirmed by point counting the percentage cells showing brown staining (Fig. 3).

\section{Bcl-2 immunoreactivity and quantification}

High levels of Bcl-2 immunoreactivity were observed in the thyroid cells of control (Fig. 4A) and goitrous (Fig. 4B) rats. The Bcl-2 immunoreactivity was present in the cytoplasm and nucleus of cells and was also clearly localised within the vasculature. High levels of $\mathrm{Bcl}-2$ were reduced in thyroids after 2 days of involution (day 16); this was quantified as 15\% immunopositivity of all cell types comprising the thyroid (Fig. 4C). The Bcl-2 activity returned to the control values after 4 and 6 days of involution (Fig. 4D, E). The immunoreactivity was quantified by point counting the number of immunopositive cells (Fig. 3).

\section{ASP immunoreactivity}

In sections from normal rat thyroids, there were low levels of ASP immunoreactivity (Fig. 5A). During goitrogenesis, ASP immunoreactivity was located both within cells of the stromal compartment (Fig. 5B) and within follicular cells. Two days after goitrogen removal, ASP immunoreactivity was increased and located within stromal and vascular tissue (Fig. 5C). 

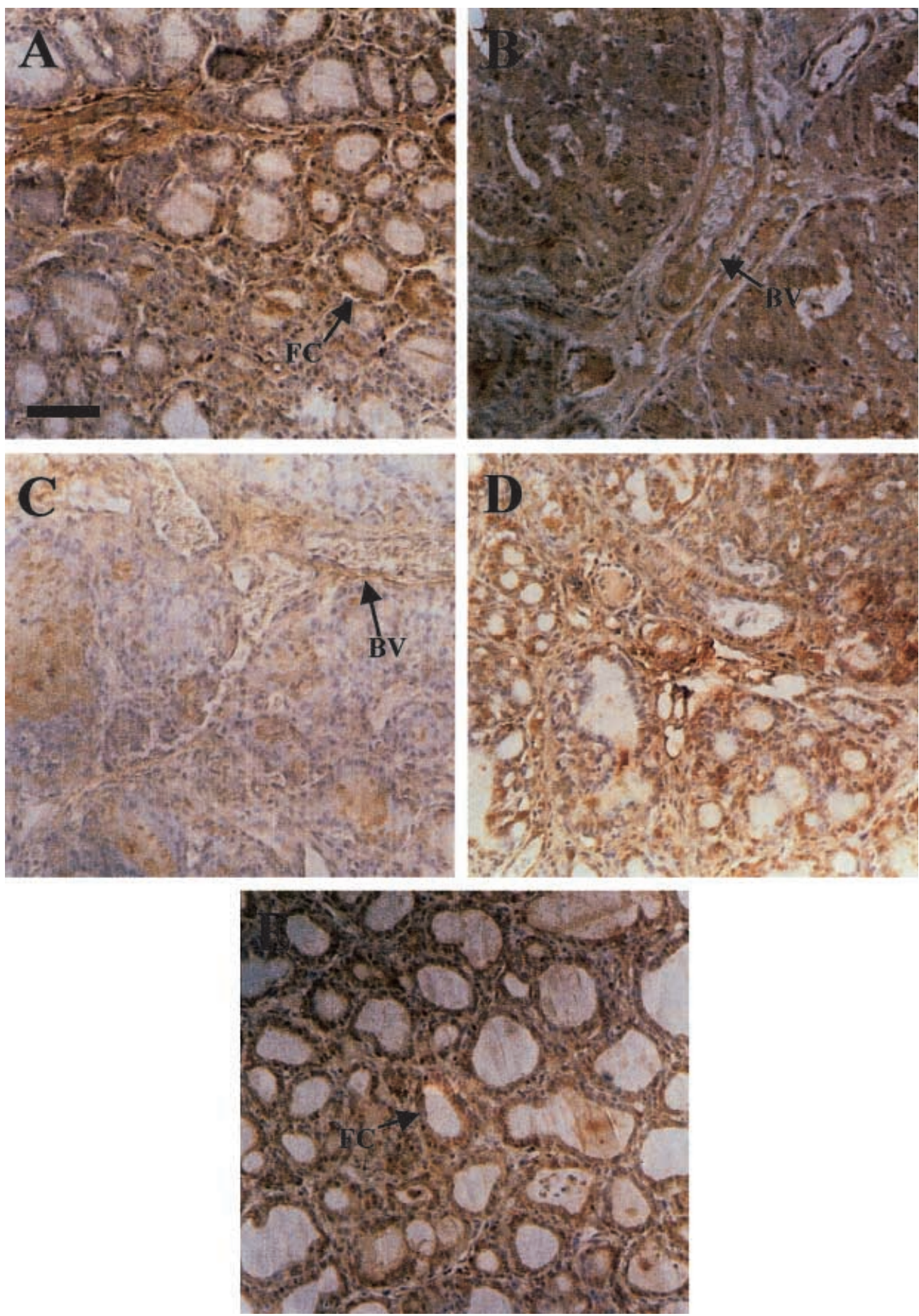

Figure 4 Immunohistochemical localisation of the anti-apoptotic factor, $\mathrm{Bcl}-2$, within rat thyroids in this model. (A) Control thyroid, showing positive (brown) immunoreactivity within follicular cells (FC); (B) day 14 goitrogenesis, showing immunoreactivity within blood vessels (BV); (C) day 16 (2-day involuted); (D) day 18 (4-day involuted); (E) day 20 (6-day involuted). Bar represents $10 \mu \mathrm{m}$. 

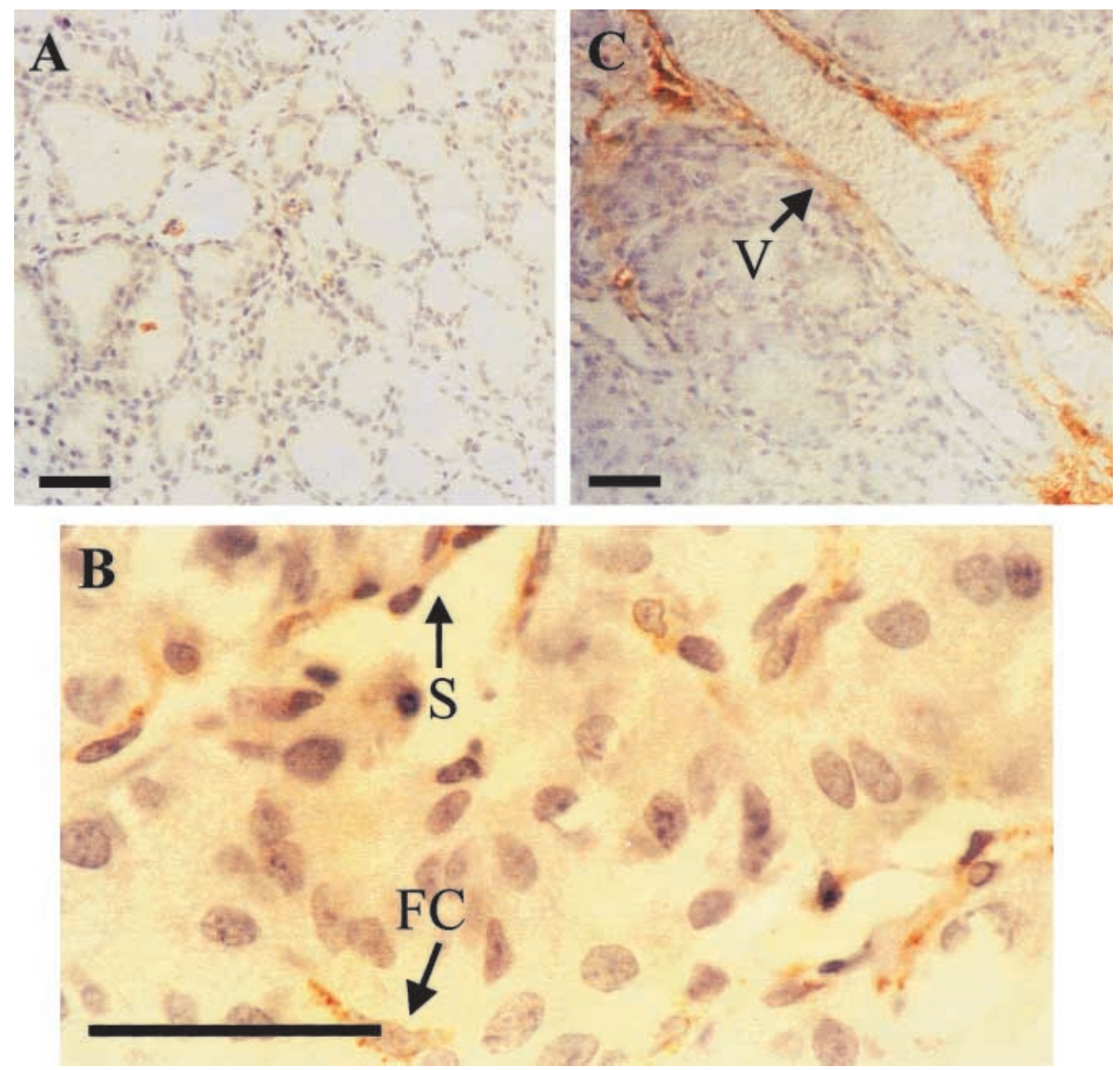

Figure 5 Immunohistochemical localisation of ASP within rat thyroid in this model. (A) Control thyroid, showing limited brown ASP immunoreactivity; (B) day 14 goitrogenesis, showing ASP localisation within stromal (S) and follicular cells (FC); (C) day 16 (2-day involuted) showing increased vascular (V) localisation of ASP. Bars represent $10 \mu \mathrm{m}$.

\section{Discussion}

After 2 weeks of a goitrogenic regimen, the rats exhibited a fourfold increase in thyroid weight. During goitre involution, the bulk of the cell loss took place between days 2 and 4 after removal of goitrogen. Whether this was the result of the decrease in thyroid-stimulating hormone (TSH) or the increase in thyroid hormone or iodide is difficult to determine, because the kinetics of the return of both of these to normal values are intimately connected. After 34 days of involution, the thyroid weight had not returned to control values, but had levelled off at twice the control weight at the same time point. This confirms the data on thyroid weight from other studies that allowed the rat thyroid to involute by returning to a normal diet
(Wynford-Thomas et al. 1982a, Logan et al. 1994). Follicular cell hyperplasia is not, therefore, a fully reversible process and, as proposed by Tachiwaki \& Wollman (1990), there may be a new and permanent population of cells that survive the involution process, conceivably because of their resistance to apoptosis.

The in situ end-labelling showed no apoptosis within control thyroids and an increase in the number of apoptotic cells within goitrous rat thyroids. This was confirmed by the ASP immunoreactivity, the majority of which localised to the stromal compartment. Apoptosis in goitrogenesis has also been observed in a previous study (Tamura et al. 1998) and is occurring despite the very high expression of anti-apoptotic Bcl-2 within the follicular cells. Thus the mechanism of the increased apoptosis during goitrogenesis 
may be independent of the Bcl-2 pathway, or there may be an excess of a pro-apoptotic member of the Bcl-2 family, such as Bax.

One contributor to the increased apoptosis during goitrogenesis is the Fas pathway (Tamura et al. 1998), in which there is increased Fas expression during goitrogenesis, coupled with constitutive expression of Fas ligand (Giordano et al. 1997). In contrast, in vitro experiments using human thyroid cells show that TSH, through cAMP, inhibits Fas expression and thus acts as an anti-apoptotic factor. Further evidence is supplied by observations that thyroid receptor antibodies in patients with Graves' disease inhibited Fas-mediated apoptosis, thus promoting the induction of goitre (Kawakami et al. 1997). This line of evidence, however, is limited to the follicular cells, and no extrapolation can be made to the stromal population in which the majority of apoptosis is occurring.

The apoptotic index of thyroids 2 days after removal of goitrogen (day 16) show a fourfold increase in the number of cells going through apoptosis. The actual number of apoptotic cells as measured by point counting was small, but such a rate of represents a significant response to the goitrogen removal and would represent a rapid decrease in thyroid cell number within a few days. Two days later (day 18), the apoptotic index had decreased, and it was between these two days that the greatest involution was observed. Bcl-2 expression was greatly reduced, both in the follicular cells and in the blood vessels of the thyroids, 2 days after goitrogen removal, and this reduction corresponded to the apoptotic response. Therefore, downregulation of Bcl-2 may provide a stimulus for the apoptotic cell death that accompanies it. The basal high level of $\mathrm{Bcl}-2$ had returned 4 days after goitrogen removal, when concentrations of thyroid hormone and TSH should have been normalised (Tamura et al. 1998). The reduction of Bcl-2 levels in blood vessels would, likewise, provide a stimulus for vascular cell apoptosis. This is consistent with the fact that there must be elimination of the increased vasculature that accompanies goitrogenic angiogenesis (Patel et al. 1996), which is no longer needed by the decreasing tissue mass.

ASP immunoreactivity was increased during goitrogenesis and on involution: after 2 days ASP was clearly found on vascular tissues. It is difficult to discriminate between cells in an involuting follicle and those in a regressing blood vessel because both show similar features, but it seems likely that the majority of the apoptosis observed with the Apoptag in situ end-labelling is in the stromal compartment. The expression of this protein is upregulated at a point before or coincident with an irreversible step in the apoptotic process. It can be detected at early stages after induction of the process, and is maintained at extremely high levels as apoptosis progresses (Grand et al. 1995). The ASP immunoreactivity can still be observed after engulfment by neighbouring cells and macrophages, therefore quantification of the immunoreactivity would give an indication of the amount of apoptosis that has and will take place, rather than the apoptotic index. Therefore the high residual levels of ASP observed after 2 days of involution indicate the large amounts of apoptosis that has occurred or is occurring at the beginning of involution.

This study has shown that there is apoptosis during goitrogenesis, and that it is greatly increased during the first few days of goitre involution. This apoptosis is primarily in the stromal/vascular tissue during involution, and accompanies the downregulation of the anti-apoptotic factor, $\mathrm{Bcl}-2$, that may provide the stimulus for the cell loss.

\section{References}

Adams JM \& Cory S 1998 The Bcl-2 protein family: arbiters of cell survival. Science 281 1322-1326.

Boise LH, Gottschalk AR, Quintans J \& Thompson C 1995 Bcl-2 and $\mathrm{Bcl}-2$-related proteins in apoptosis regulation. Current Topics in Microbiology and Immunology 200 107-121.

Giordano C, Stassi G, De Maria R, Todaro M, Richiusa P, Papoff G, Ruberti G, Bagnasco M, Teati R \& Galluzzo A 1997 Potential involvement of Fas and Fas ligand in the pathogenesis of Hashimoto's thyroiditis. Science 275 960-963.

Grand RJA, Milner AE, Mustoe T, Johnson GD, Owen D, Grant ML \& Gregory CD 1995 A novel protein expressed in mammalial cells undergoing apoptosis. Experimental Cell Research 218 439-451.

Green DR \& Reed JC 1998 Mitochondria and apoptosis. Science 281 1309-1312.

Hsu SM, Raine L \& Fanger H 1981 Use of avidin-biotin peroxidase complex $(\mathrm{ABC})$ in immunoperoxidase techniques: a comparison between $\mathrm{ABC}$ and unlabelled antibody (PAP) procedures. Journal of Histochemistry and Cytochemistry 29 577-580.

Kawakami A, Eguchi K, Matsuoka N, Tsuboi M, Urayama S, Kawabe Y, Tahara K, Ishikawa N, Ito K \& Nagataki S 1997 Modulation of Fas-mediated apoptosis of human thyroid epithelial cells by IgG from patients with Graves' disease (GD) and idiopathic myxoedema. Clinical and Experimental Immunology 110 434-439.

Kerr JF, Wyllie AH \& Currie AR 1972 Apoptosis: a basic biological phenomenon with wide-ranging implications in tissue kinetics. British Journal of Cancer 26 239-257.

Kotani T, Aratake Y, Hirai K, Fukazawa Y, Sato H \& Ohtaki S 1995 Apoptosis in thyroid tissue from patients with Hashimoto's thyroiditis. Autoimmunity 20 231-236.

Logan A, Smith C, Becks GP, Gonzalez A-M, Phillips ID \& Hill DJ 1994 Enhanced expression of transforming growth factor-(1 during thyroid hyperplasia in rats. Journal of Endocrinology 141 45-57.

Manetto V, Lorenzini R, Cordon-Cardo C, Krajewski S, Rosai J, Reed JC \& Eusebi V 1997 Bcl-2 and Bax expression in thyroid tumours. An immunohistochemical and western blot analysis. Virchows Archives 430 125-130.

Moore D, Ohene-Fianko D, Garcia B \& Chakrabarti S 1998 Apoptosis in thyroid neoplasms: relationship with p53 and bcl-2 expression. Histopathology 32 35-42.

Pan G, O’Rourke K \& Dixit VM 1998 Caspase-9, Bcl-XL, and Apaf-1 form a ternary complex. Journal of Biological Chemistry 273 5841-5845.

Patel VA, Hill DJ, Eggo MC, Sheppard MC, Becks GP \& Logan A 1996 Changes in the immunohistochemical localisation of fibroblast growth factor-2, transforming growth factor-beta 1 and thrombospondin-1 are associated with early angiogenic events in the hyperplastic rat thyroid. Journal of Endocrinology 148 485-499.

Pollina L, Pacini F, Fontanini G, Vignati S, Bevilacqua G \& Basolo F 1996 Bcl-2, p53 and proliferating cell nuclear antigen expression is 
related to the degree of differentiation in thyroid carcinomas. British Journal of Cancer $\mathbf{7 3}$ 139-143.

Reed JC 1998 Bcl-2 family proteins. Oncogene 17 3225-3236.

Riesco JM, Juanes JA, Carretero J, Blanco EJ, Riesco-Lopez JM, Vazquez G \& Vazquez R 1998 Cell proliferation and apoptosis of thyroid follicular cells are involved in the involution of experimental non-tumoral hyperplastic goiter. Anatomy and Embryology (Berlin) 198 439-450.

Tachiwaki O \& Wollman SH 1990 Comparison of a special class of epithelial cells in hyperplastic thyroids undergoing involution and in thyroids in hypophysectomized rats. American Journal of Anatomy 189 57-61.

Tamura M, Kimura H, Koji T, Tominaga T, Ashizawa K, Kiriyama T, Yokoyama N, Yoshimura T, Eguchi K, Nakane PK \& Nagataki S 1998 Role of apoptosis of thyrocytes in a rat model of goiter. A possible involvement of Fas system. Endocrinology 139 3646-3653.

Tanimoto C, Hirakawa S, Kawasaki H, Hayawaka N \& Ota H 1995 Apoptosis in thyroid diseases: a histochemical study. Endocrine Journal 42 193-201.

Wollman SH \& Breitman TR 1970 Changes in DNA and weight of thyroid glands during hyperplasia and involution. Endocrinology 86 322-327.
Wynford-Thomas D, Stringer BM \& Williams ED 1982a Desensitisation of rat thyroid to the growth-stimulating action of TSH during prolonged goitrogen administration. Persistence of refractoriness following withdrawal of stimulation. Acta Endocrinologica 101 562-569.

Wynford-Thomas D, Stringer BM \& Williams ED $1982 b$ Goitrogeninduced thyroid growth in the rat: a quantitative morphometric study. Journal of Endocrinology 94 131-140.

Zamzami N, Marzo I, Susin SA, Brenner C, Larochette N, Marchetti, P, Reed J, Kofler R \& Kroemer G 1998 The thiol crosslinking agent diamide overcomes the apoptosis-inhibitory effect of Bcl-2 by enforcing mitochondrial permeability transition. Oncogene $\mathbf{1 6}$ 1055-1063.

Zou H, Henzel WJ, Liu X, Lutschg A \& Wang X 1997 Apaf-1, a human protein homologous to C. elegans CED-4, participates in cytochrome c-dependent activation of caspase-3. Cell 90 405-413.

Received 26 July 1999

Revised manuscript received 30 September 1999 Accepted 1 October 1999 